\title{
Julie Dickerson: Creative Currents
}

Interviewed by Ashley Makar

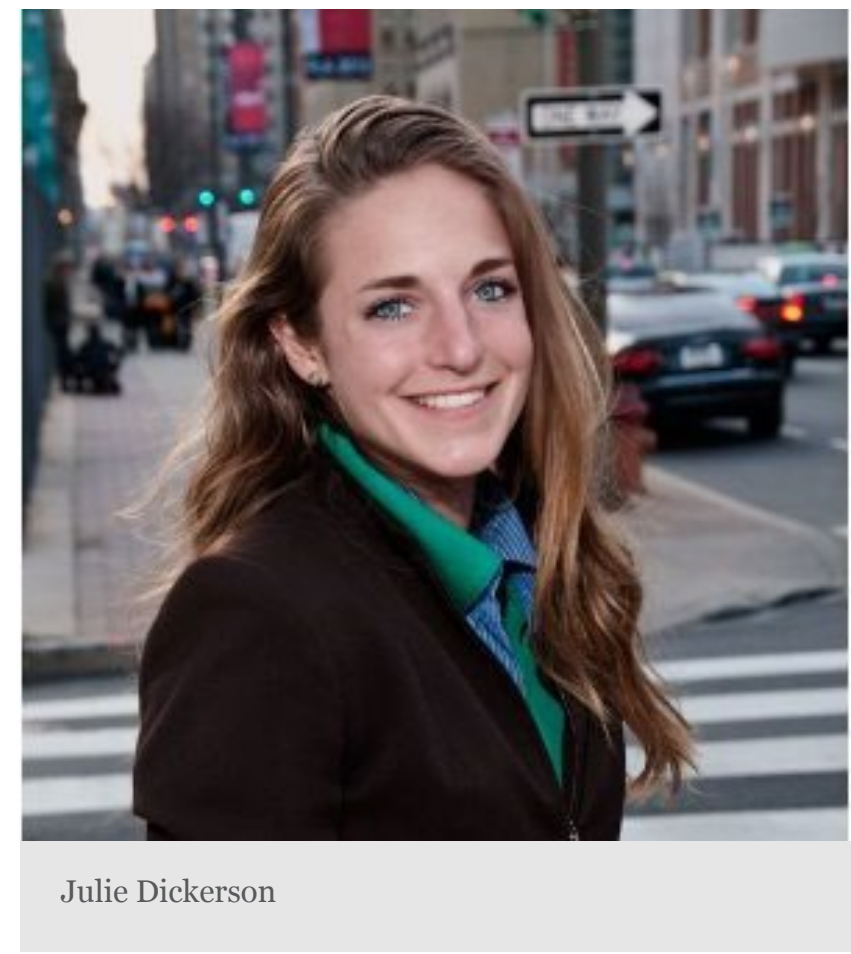

Ashley Makar interviewed Julie Dickerson in 2010 while she was painting a mural of "dancing saints"-ranging from Moses' sister Miriam to Martin Luther King-in the undercroft at St. James and St. Paul Episcopal Church in New Haven, Connecticut (affectionately nicknamed "St. PJ's"). Dickerson is a 2010 graduate of Princeton University. As a senior, she submitted a proposal for Princeton's Martin A. Dale '53 fellowship, which "enables an outstanding Princeton senior to devote the year following graduation to an independent project of extraordinary merit that will widen the recipient's experience of the world and significantly enhance his or her personal growth and intellectual development," according to the Princeton website. Dickerson was granted the fellowship for her project titled "Creative Currents," in which she proposed to paint as many murals as possible in hospitals, shelters, and other community spaces in the New York/ New Jersey area.

Ashley Makar: What is your background in the arts?

Julie Dickerson: I began in high school and continued taking classes in college and then I applied for this fellowship this year.

Ashley Makar: Were you a studio art major at Princeton?

Julie Dickerson: I was an art history major but I took a lot of classes in visual arts, about half; my thesis was actually a visual arts show. So I'm technically art history but I was 
basically a studio art major.

Ashley Makar: And what is your spiritual background? What was your experience growing up?

Julie Dickerson: I'm Christian. We went to church every Sunday, and my mom was a Sunday school teacher for a while. I would say it's a pretty big part of my life; I notice it if I don't go to church for a week. It messes up my schedule if I don't go. I've been to mostly Protestant [churches] I guess.

Ashley Makar: What, if any, do you think is the relationship between your background in the arts and your religious background?

Julie Dickerson: I don't know if there is necessarily a really strong one other than that I feel I have this talent, and God would want me to use it. I have a hard time doing art just to do art. I much prefer to do it for someone else. So if people say "Oh, I want a portrait of my daughter," or "I want a portrait of my dog," it's a lot more fun to do it for people than just for myself because it gets boring just for myself. Half the joy of it is seeing other people get excited about it.

Ashley Makar: Do you engage in spiritual practices?

Julie Dickerson: I pray, and I go to church, and I enjoy that.

Ashley Makar: Please discuss any encounters you've had with images and/or objects that you consider to be of spiritual significance.

Julie Dickerson: I don't think I have anything like that. I tried to take a class on Byzantine art, which is a lot of the icons and stuff, and I honestly found it to be very boring. Everything looked the same to me. I know a lot of people have different experiences and very much like those icons and those images. My favorite painting is Saint George and the Dragon. That's my favorite. I think it's because I was always into fantasy stuff as a kid, and I really like narrative stuff. I like illustration sometimes more than "fine art." So I like it because it is illustrative, and there actually is a saint in there, but I think what I like more is that there is a knight and a dragon. I mean, there are definitely images that speak to me, but even though I go to church and pray and do that kind of stuff my spirituality is linked to other things too. For example, I really like to run. Whenever I run or am in nature, sometimes I feel more spiritual then than when I am in church, even though I really like both.

Ashley Makar: How about when you are doing art?

Julie Dickerson: Yes, I would say so. It feels good to use a talent. Honestly, I think being outside and exercising a little more so than art, but I definitely feel a sense of peace [when doing art]. 


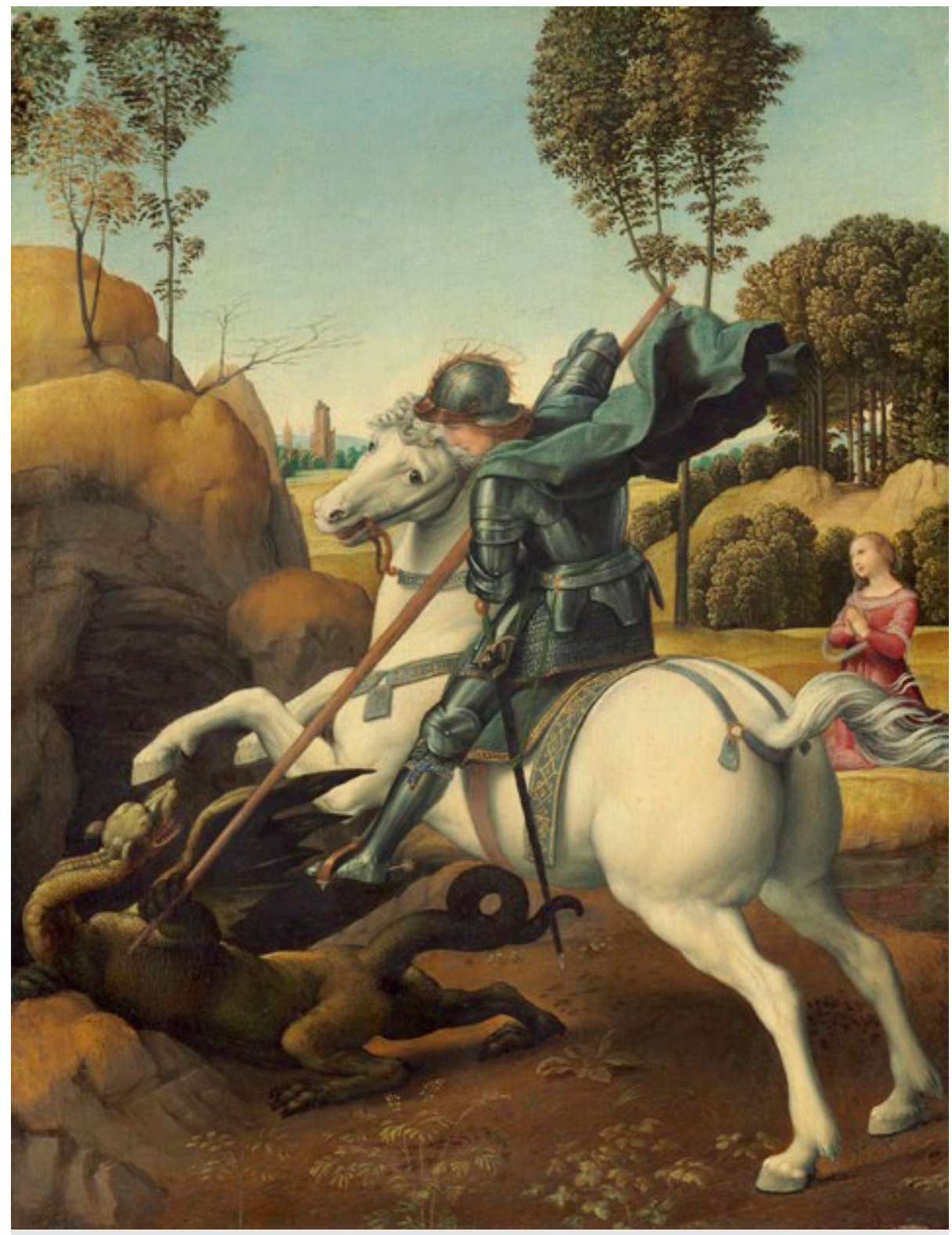

Raphael, St. George and the Dragon, c. 1506

Ashley Makar: What do you think is the role of images and/or objects in the lives of an individual or community engaged in spiritual practice?

Julie Dickerson: It really depends. For Catholicism, I think, it means a lot more. But then you do have stained glass windows. Images or the lack of images: you could go on forever about what that means or doesn't mean for different religious groups. Historically people either wanted images to help them focus on god or they thought images were distracting. I can't really answer that question because there are a whole slew of answers depending on who you are that you would say. Personally, I like when there are images in church because, to be honest, sometimes the sermon isn't the most interesting and it's nice to have interesting things to look at. 
Ashley Makar: What, if any, has been your experience working with individuals or communities engaged in religious practice?

Julie Dickerson: I actually went into this project not necessarily intending to work with [religious] communities, basically [I planned to work with] women's shelters, homeless centers, hospitals, that sort of thing. But churches and religious groups are so involved in that aspect of society. Almost every place had some kind of religious component to it. Either it was funded by, or run by, or had volunteers that came from religious groups. So my experience has always been very positive. People will sometimes complain about the Church, "oh, the Church this, the Church that," and the Church certainly isn't perfect, and there are obviously some issues that I have with some churches as well, but I got to say, I honestly don't know where some of these people would be if religious communities weren't involved in these places. My experience has been extremely positive because I'm seeing the real activism side of it. Here at St. PJ's has been incredible because there are so many different non-profits that use the space down here. It's in a church, but definitely not all the people that come here are religious. Seeing the church in the community working for positive goals for people who aren't even necessarily religious-I think that's extremely important.

Ashley Makar: Not just for other Christians.

Julie Dickerson: And I don't think it should be working just for Christians. When I was first invited to paint this mural [at St. PJ's] I was like, "Well that's awesome, but I can't

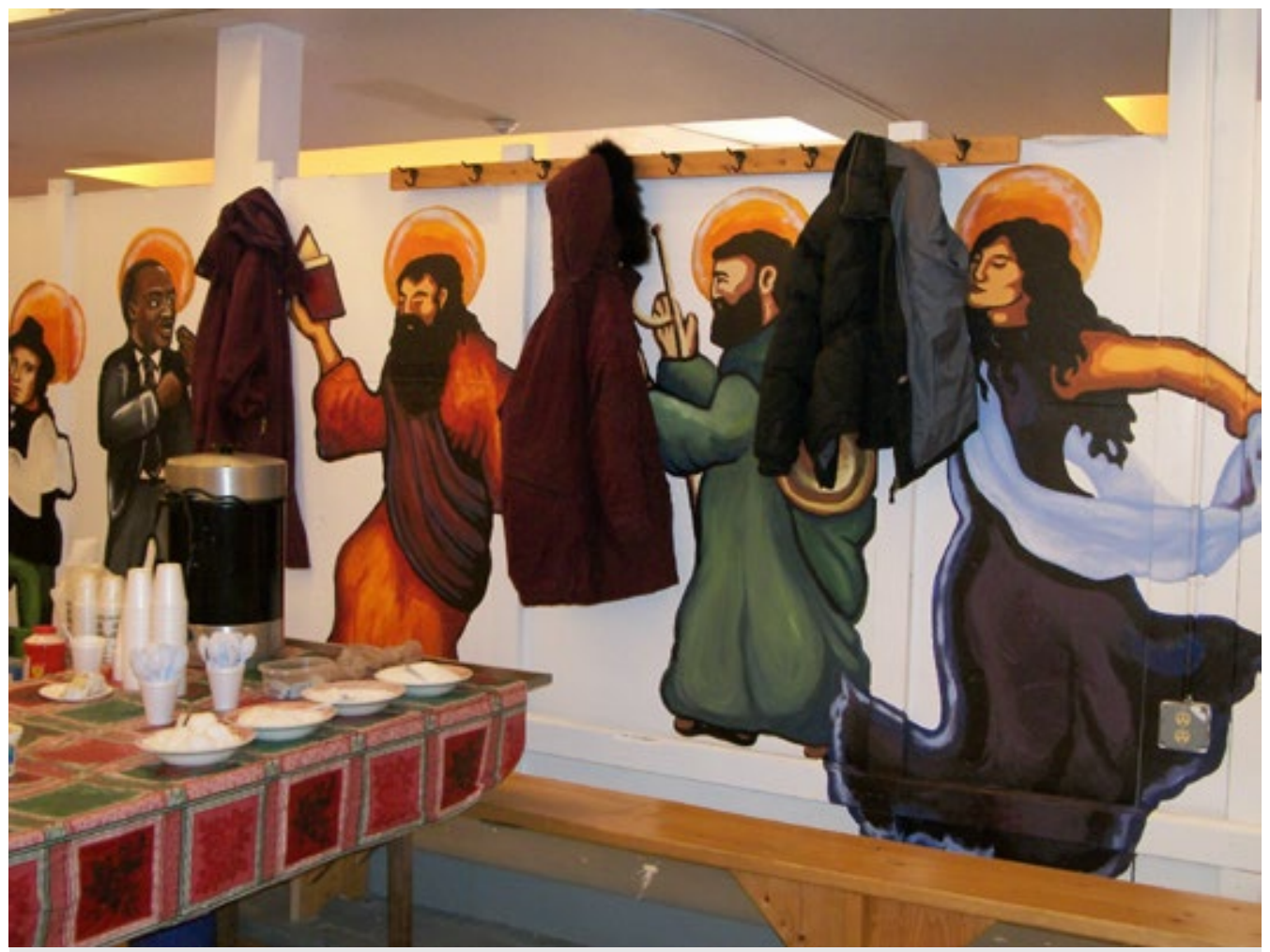

Julie Dickerson, Dance with the Saints mural, St. Paul and St. James Church, New Haven, CT, 2010 


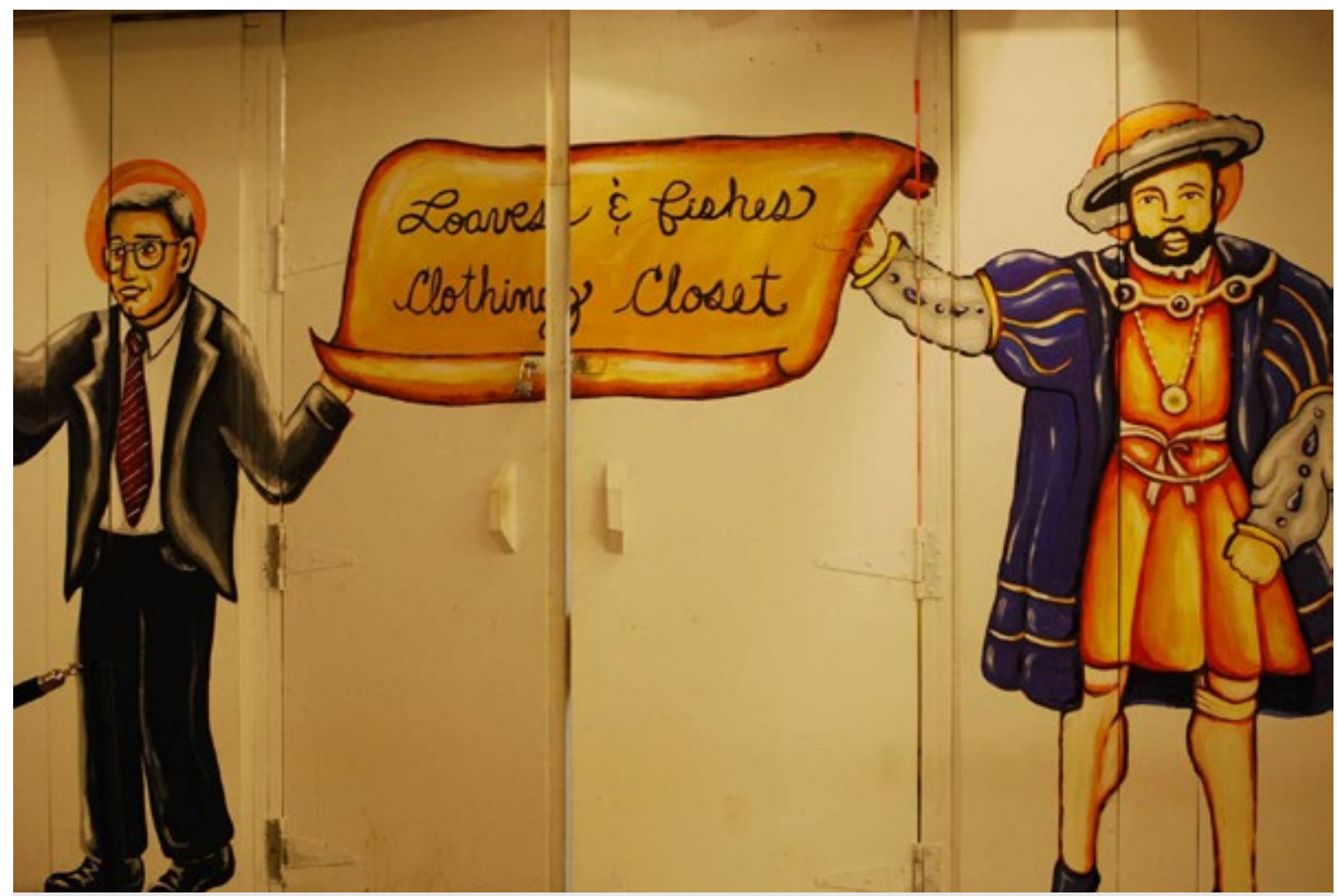

Detail of Dickerson's Dance with the Saints mural

just paint a church to paint a church, it's got to have some sort of other thing going on." This is not just for Christians. As soon as I walked in, however, and saw the bulletin board outside of Alex's office, ${ }^{1}$ I thought, "Wow, this is a good church," because of all the different events they had on there: benefiting different groups, auditions for choirs, all different avenues to help out. I can't even name them all. I was like, "Wow, I know this is a small church, but they're doing all these different things, I feel really great about coming here and painting, because it's going to help so many people and brighten up so many peoples' days."

Ashley Makar: What is the role of sensory experience in the making (and consuming) of images and/or objects?

Julie Dickerson: I think for me, after a while, I get tired of looking at it [the art], because I see all the mistakes. I see everything that's wrong with it. But the reason I enjoy doing this kind of community art is because the experience expands from just a visual "Where do I want to put this line, what color is this," to a whole different sensory experience. Even for NA [Narcotics Anonymous] here. There's one woman who comes up every day and gives me a hug and a kiss. That's how seeing this makes her feel; it's very different from what I see and how I feel. I think everyone has a different reaction to seeing art. In this one elderly place that I painted, most of the people were immigrants either from Puerto Rico or from China, so on the walls I painted images of where they came from. Some of them who could not remember me from [one day to the next]: "Why are you-? What are you doing to our wall?” I would respond, "I was here yesterday, Mrs. So-and- 


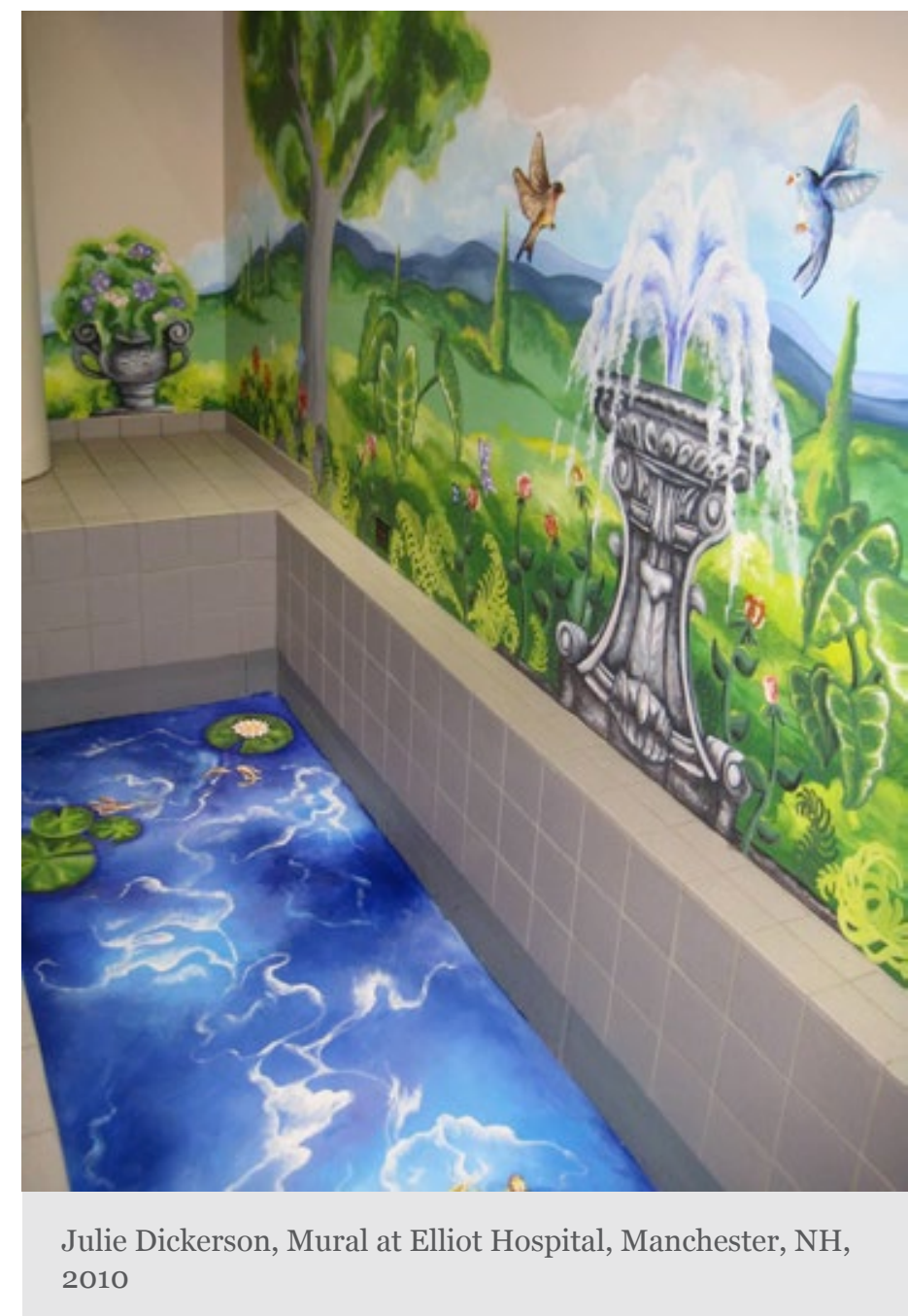

so." Couldn't remember that, but then when they saw their homeland on the wall they would really remember that. So it depends on who you are. For some people it evokes an entire memory set. For other people, they don't even know who these saints are that I'm painting, but the fact that someone cared enough to put people on these walls is enough for them.

So for everyone it's going to evoke a totally different sensory experience. For me as the artist it's always nerve-wracking because you never know what kind of reaction you will get. Obviously when people are excited and hugging me I'm like "Alright, good. Good, good, good." [At the elderly home,] we found out exactly where they were from, [but] sometimes they would want me to put a different spin on it. So this one woman said, "I really want this sun to have rays." And I said, "Okay, that's not realistic, but whatever. You say jump and that's what I do because it's your mural; it's for you." So I did this, and she loved it. Then this older Chinese man, he didn't speak English, but he was shaking his hands and shaking his head. Clearly he doesn't like it, but she's going, "He loves it!" And I was like, "I don't know if he loves it ..." Eventually she understands that he really doesn't like it and I don't know what to do. Eventually she goes, "Those Asians, they don't know how the sun really is. Us from Puerto Rico, we know. You leave it." So I said, "I'm leaving it up to the administration, they can decide whether the sun has rays 
or not." People have very strong opinions about visuals because they mean different things to different people. Working off a photograph is always good, but, at a certain point, departing from it to take people's suggestions and make it more yours or more theirs, that's kind of the fun part.

Ashley Makar: What role, if any, does physical environment or nature play in your artistic work?

Julie Dickerson: It makes a huge difference, environment changes everything. Even the wall surface changes everything. In a lot of places they're not nice places, there's cinderblock, and outlets, and pipes, and so that means I have to come up with a design that I can [place] over it and still have it look good with all the bumps. And have it so you don't notice the outlet, or so that the outlet is part of it. Or even, in this one, dealing with this bar that pops out.

Ashley Makar: Yes, that's tough.

Julie Dickerson: At first I thought this could be a really negative environmental factor.

Ashley Makar: Yes, because you have to back up to see how it's going to look.

Julie Dickerson: To see it perfectly. But, thank goodness, a lot of people have said, "Oh well we really like that when you go from the side it looks really different," because it really [does.] So that's a good environmental thing that I did not know would necessarily [be]. [The] mirror changes things cause you see yourself with the saints. Then, also, there's

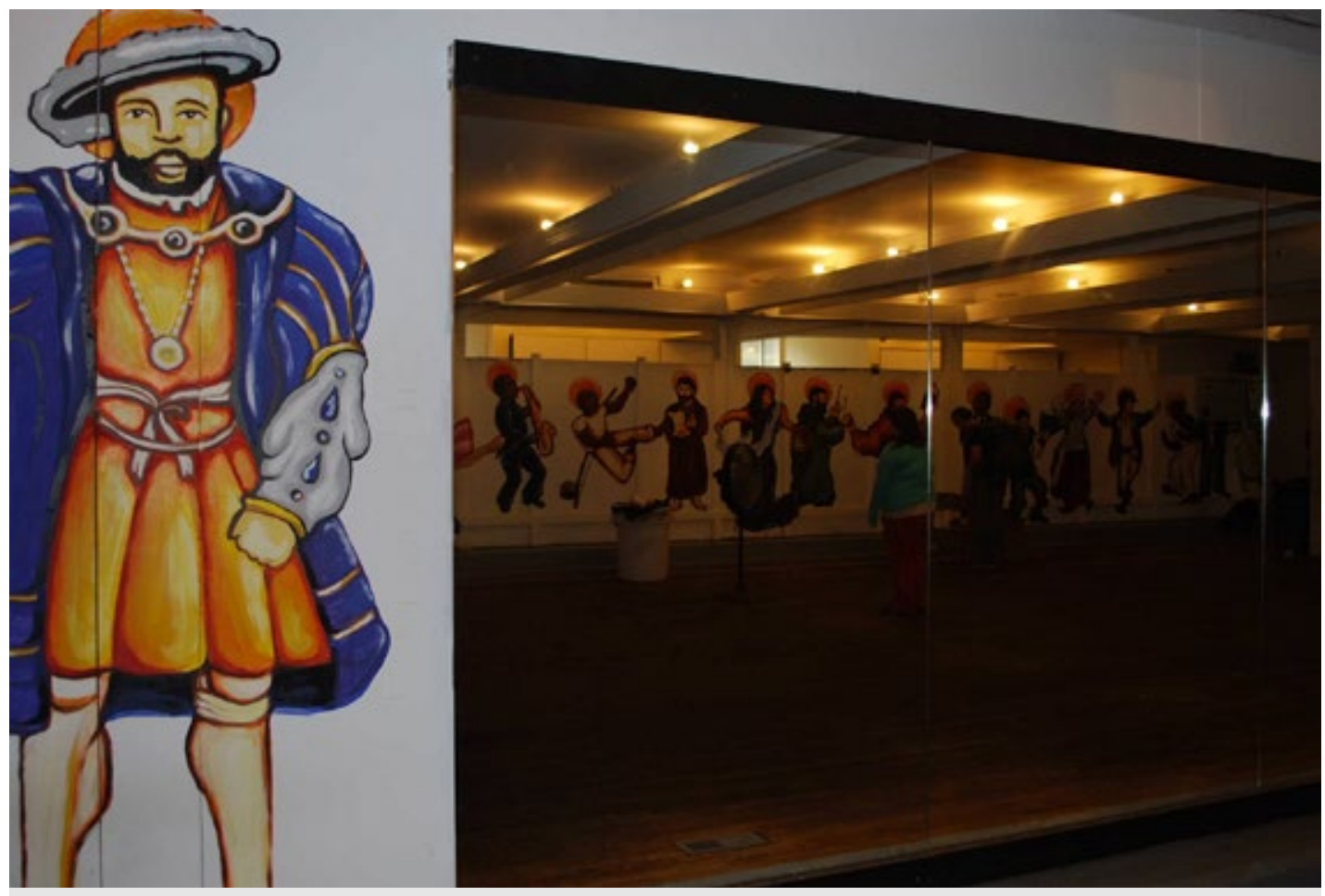

Detail of Dickerson's Dance with the Saints mural, showing the mirror 
environment in terms of the climate at a women's shelter. The women's shelters usually want things that are very different from, say, a place where people are trying to get their GEDs. They don't want the same things at all.

Ashley Makar: What kinds of things do they want at women's shelters?

Julie Dickerson: Women's shelters, they definitely like gardens, really peaceful things, more nature scenes. Especially because a lot of them have kids, and that's something both the women and the kids can really like. Places that are teaching people to get their GEDs want something more inspiring. Not that one's more inspiring than the other, but they want inspirational quotes or they want things that reflect what their place is about. So shelters are about refuge, peace, and getting your GED is not necessarily about that; it's about pushing yourself out of your comfort zone.

Ashley Makar: In what ways do you address space and movement in your work?

Julie Dickerson: Knowing how people move impacts the space, design. In one place [I painted] there is this kind of this stage area. People don't really go up onto the stage area, they just look up into it, and there would be a little podium where people would give speeches from. Whatever I put up there needs to be, one, not too distracting as a background where, when people are speaking in front of it it's not very distracting, at the same time it has to be worthy of a podium-like place. So it has to accentuate that importance and not distract from it, which is sometimes a hard balance. Or even just in terms of perspective. People are walking up the stairs. You need to be walking up and down the stairs as you are painting the murals so you know how each section looks. It may look fine if you are sitting in front of it, but, [you] want to say, "Okay, when people are walking up the stairs they need something right here." Then, of course, within the piece itself you want to make sure that it has rhythm and movement and pattern and color and all that good stuff.

Ashley Makar: Do religious images, themes, and/or questions inform your work?

Julie Dickerson: I think you could relate anything to [Christianity] if you wanted to, gardens and stuff. All you have to do is think of Psalm 23 "He makes me lie down in green pastures, he leads me beside still waters ...." I think what I wanted to do this year was push myself to interact with a group of people who had I never interacted with, and say, that's what Christ did: he interacted with all kinds of people. I feel like I've interacted with a lot of kinds of people in my school and college, but I've never had the chance to interact with people who have had really hard times. So I guess you could relate it to that. But I'm not sneaking religious imagery into my gardens or anything like that.

Ashley Makar: Maybe your approach, but not necessarily what you paint. That's what I was really interested in-your approach of doing community work with the fellowship.

Julie Dickerson: Our motto is “Princeton in the nation's service and the service of all 


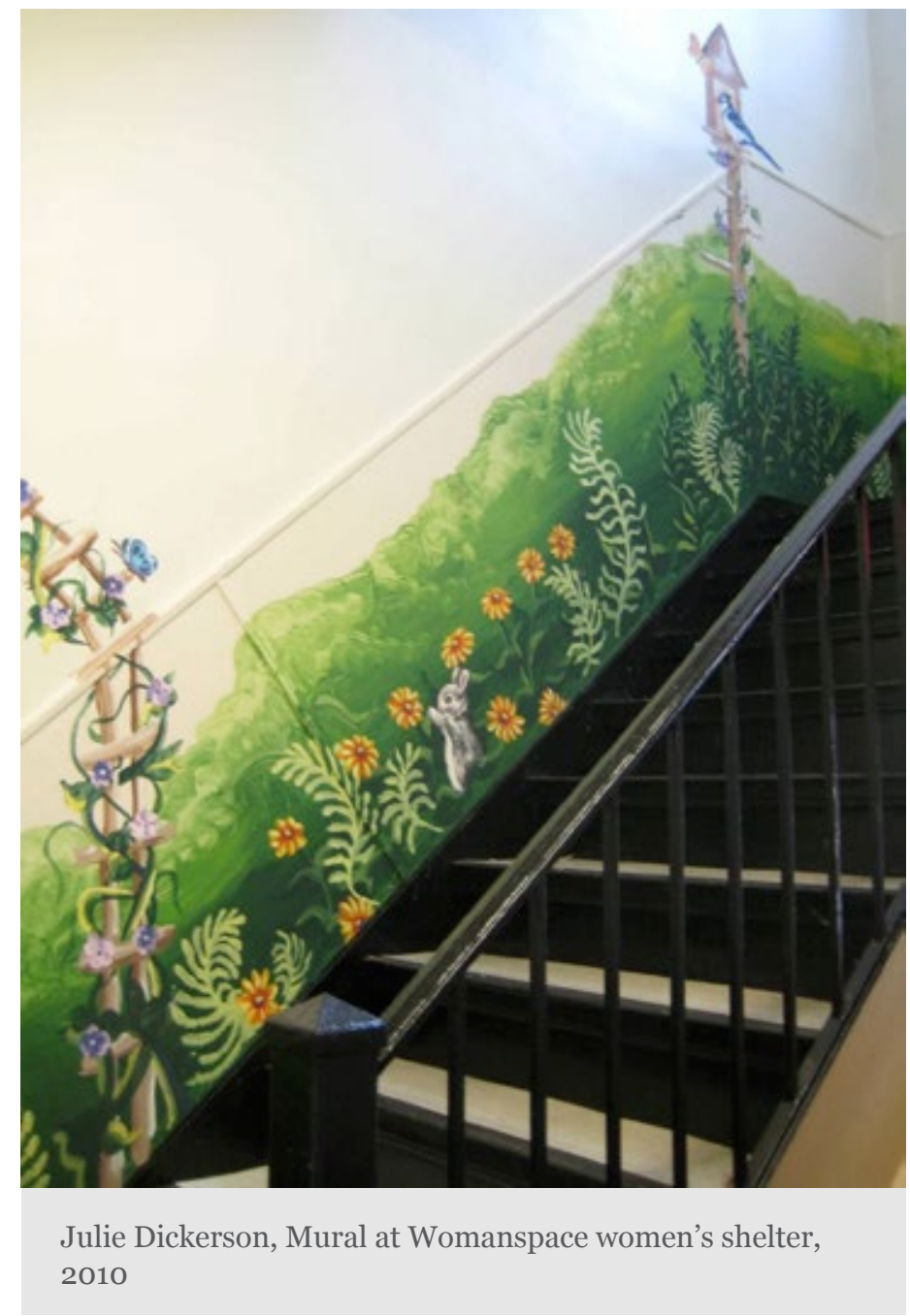

nations," but most of the time you think of that as being like, "oh well we do that through being really smart in specific fields." And by being really smart in that specific field somehow that trickles down and benefits people. I think that it does, but not in the immediate sense where I go into places and they say "Wow, councilwoman so and so approved funding for us to redecorate the place and it has been three years and you show up and now you [show up ... .]" There is satisfaction in this project in that I can do something immediately. People being really smart in a certain field obviously helps but I don't know if everyone gets that satisfaction of an immediate impact.

Ashley Makar: And you don't get those encounters.

Julie Dickerson: No, and you don't get those encounters. I was really surprised when I got this because I had tried to do different community service things at Princeton. I had said, "Why don't we auction off the artwork that's left over at the end of the year from these classes?" It's good stuff, but people just don't have room for it. Let's auction it off. Well, there's some sort of technical problem with that. You know, you come up with these community service ideas and if it hasn't already been done for whatever reason ... people just, I don't know what it is, they just don't usually do it. Actually, our class at Princeton is, hopefully, as long as we organize everything and get our act 


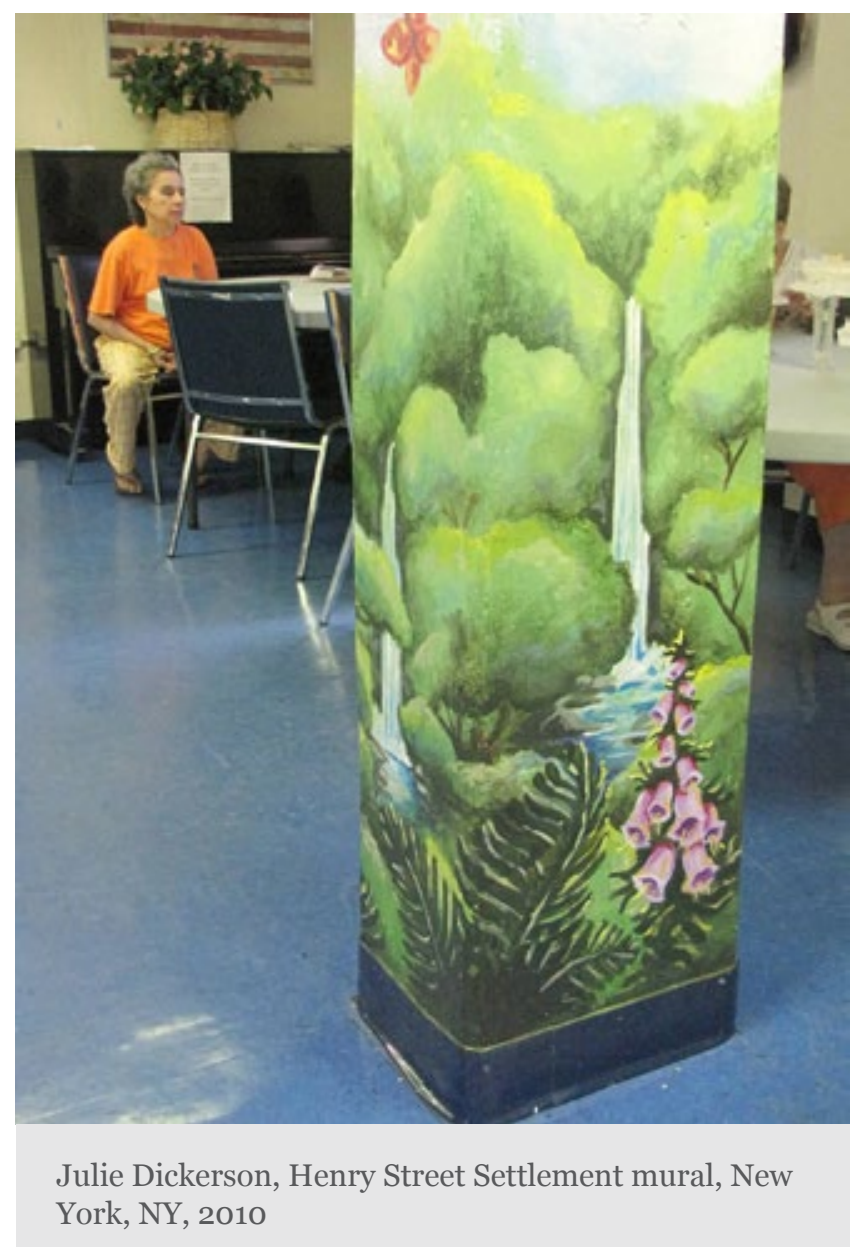

together and organize it, is going to be the first class to organize a community service event during reunions. Princeton does do a lot for the world and for people just by the people it turns out; and there are tons of people who do volunteer at Princeton, but I think there definitely is a perception that that's not first priority. I think that that will hopefully change because there are so many people who do think that's important. But I was surprised to get it [the fellowship] at the same time. I thought, not that art's not intellectual, but I don't know ...

But this type of project has a lot of personal transformative aspects to it. I think that's also what they're interested in. In seeing, if we let you do what you want for a year, how's that going to change you? And it has, because I would love to go to law school. I see what a lot of these organizations go through just trying to wade through bureaucratic mess, and I would feel pretty good about myself if I could just help them get through some of that.

Ashley Makar: Has spirituality played a role in your training, artistic or otherwise?

Julie Dickerson: Just as we were talking about before, "something you love." When it's something like you feel God has given you a specific gift for, I think it's hard not to feel the way I [do]. I mean, sometimes you get tired of it, as you do with anything, but more often than not you feel good about it. In terms of athletics, which I also love, I think 
because it strips away so many distractions, both art and athletics. You're like I'm just focusing on placing one foot in front of another, or you're just focusing on one patch of color right now, you're not thinking about anything else. I think that leaves a lot of room for reflection even though you don't know that it's happening. That definitely does feel spiritual.

Ashley Makar: That sort of alignment between action and reflection.

Julie Dickerson: I always have trouble with the story of Martha and Mary. ${ }^{2}$

What's wrong with people who do things? I don't think that's what that story is saying, but I think that's how it gets framed a lot when it's taught. Martha clearly wasn't enjoying what she was doing if she was upset people were doing other things. You know, I don't care if someone helps me with this or not, I'm just happy doing it right here. I don't like how it gets framed as, “Oh, doers aren't good because you should be sitting and praying." I think God has given everyone a different way to connect to him spiritually, and why not through what you love or what you're good at? It just doesn't make sense to me that that is an unacceptable way or that there's one set way that is the most right or the most spiritual. I think it is definitely possible to pray without using words. Sometimes I'm far more effective at that than at praying aloud or using the perfect words, which I don't think God cares about, personally. He cares about thoughts. You don't have to say the perfect thing to him.

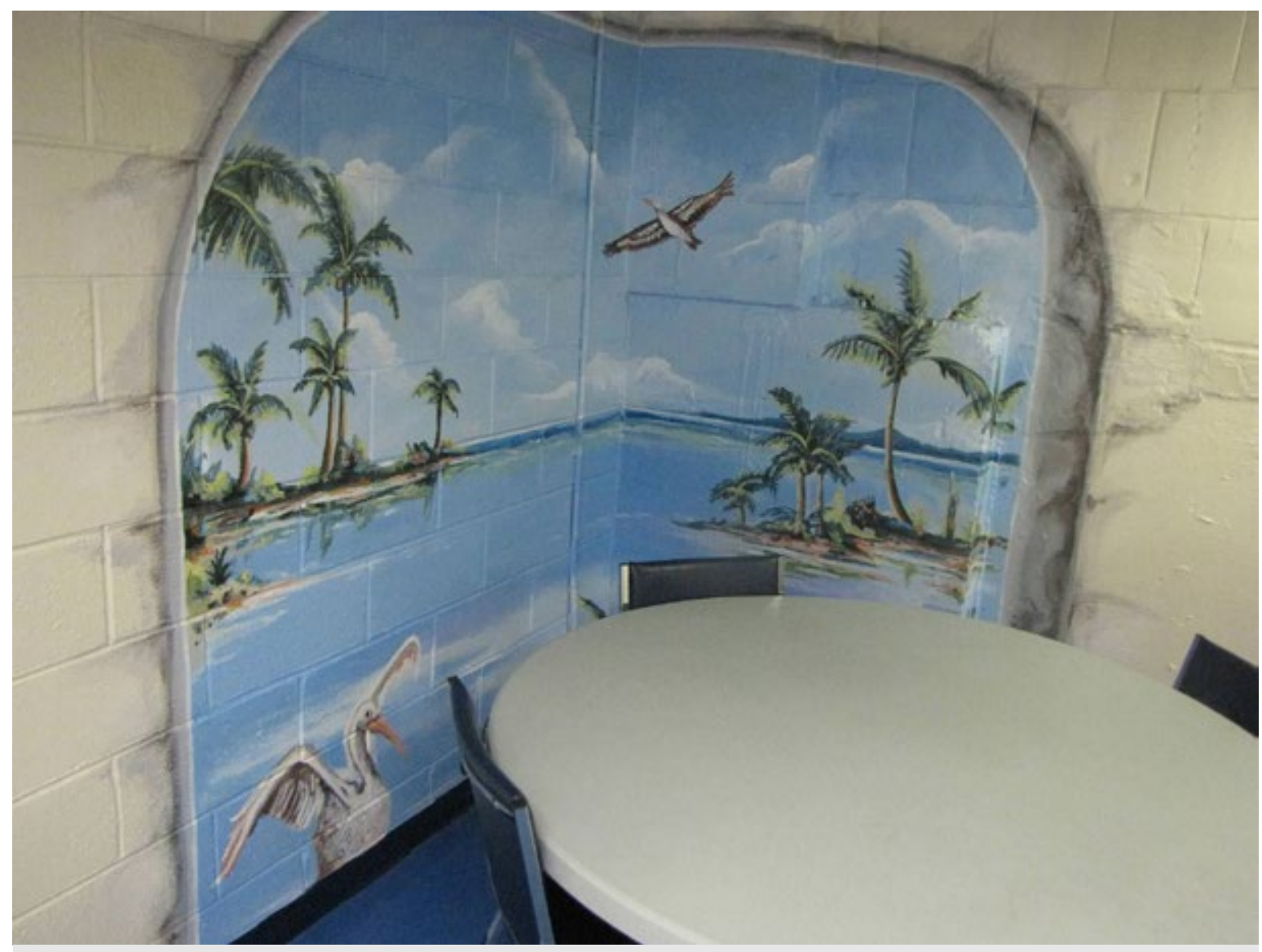

Julie Dickerson, Henry Street Settlement mural, New York, NY, 2010 
Ashley Makar: How do you think about audiences' interactions with the images and/or objects?

Julie Dickerson: Well, for me, because I usually show up every day for a set period of time, I get to see how they interact with them as it evolves, which is really cool. It's also nervewracking though because you want them to really like it. Paramount even over whether or not its good art, I want them to be happy, and that is not necessarily something that is an aspect of fine art at all. It's supposed to be like, "this is good art, and you should learn to enjoy it," but my project, while it is about creating good art, it's more about the whole social aspect of it, and how people interact with it. It's about addressing a need, what do they need and what can I give them? I usually talk to people, I spend time interacting with them. In some shelters I spend time with the kids, interacting with them, which definitely slows down the mural a lot, but at the same time, it would defeat the purpose of the whole project if I was like, "Sorry kids, I'm not going to pay attention to you." Now, of course, there are time limits and those have to be respected, but I've let kids paint in sections of the mural, cover it up when they're not looking, but you know, they feel like it's theirs, and that's more important than my distress over how awful it is at the moment. The fact is, it's paint, you can paint over it, and that's what you should be thinking about. That does not mean it's easy to do at all, because you're always like, "Oh no, here comes another kid," but you're like, "Alright this is why I'm doing this project this year, so get used to it." One kid actually locked me in the courtyard right outside the women's shelter so I couldn't leave. Then he tried to come on the subway with me out the door. It's just so cute, but. He was about five. He was very smart.

Ashley Makar: And brave.

Dickerson: Well, he was crazy. He also wanted me to put monsters in the mural, but I told him I unfortunately can't afford [to do that]. It was of sunflowers and a rainbow over a lake.

Ashley Makar: You can’t just drop in some monsters.

Julie Dickerson: I told him, "There are other kids who that might scare." And he said, "No."

Ashley Makar: Do you consider the potential for building bridges as an artist among spiritual communities themselves, and also among religious groups?

Julie Dickerson: I'll give you an example: this one building that used to be a Jehovah's Witnesses church. It was no longer a Jehovah's Witnesses church, now [hosted] classes for people [to get their GEDs]. The whole building needed sprucing up. A Jewish group contacted me and said "Hey can you paint a mural." There were people working there who were still Jehovah's Witnesses, some people who weren't at all.

Ashley Makar: Working there teaching GRE classes? 
Julie Dickerson: Right, or just doing administration stuff. Then, you've got a Jewish group that comes in, and who knows what religion the people are who are there [taking classes]. So there's already an interaction in the spaces I walk into. A lot of times I would say I'm more a connection between the administration and the people as opposed to religion and a population, but, as I said, a lot of these administrations usually have some connection to a religious group. What you see are a lot of different religious groups joining forces to interact with the community and I just have a skill that they don't have or they would be doing it already, so I just step in for a little while.

Ashley Makar: You play a mediator's role.

Julie Dickerson: Yes, and also mediating the visions of the people there and the administration. People always have opinions and will come up and tell you them. Sometimes they're good ones. Sometimes they're not, and doesn't matter. I do try and do them if I can. I do have to balance what the people who ask me to come in and do stuff want and what the people want. Most of the time it's the same thing, but ... it is hard sometimes. But, you know, it's not in my living room. I don't necessarily see it again. I would much rather see them smiling than have a picture on my blog that I kind of prefer.

Ashley Makar: Is there the potential for controversy when engaging with religious practices and/or content?

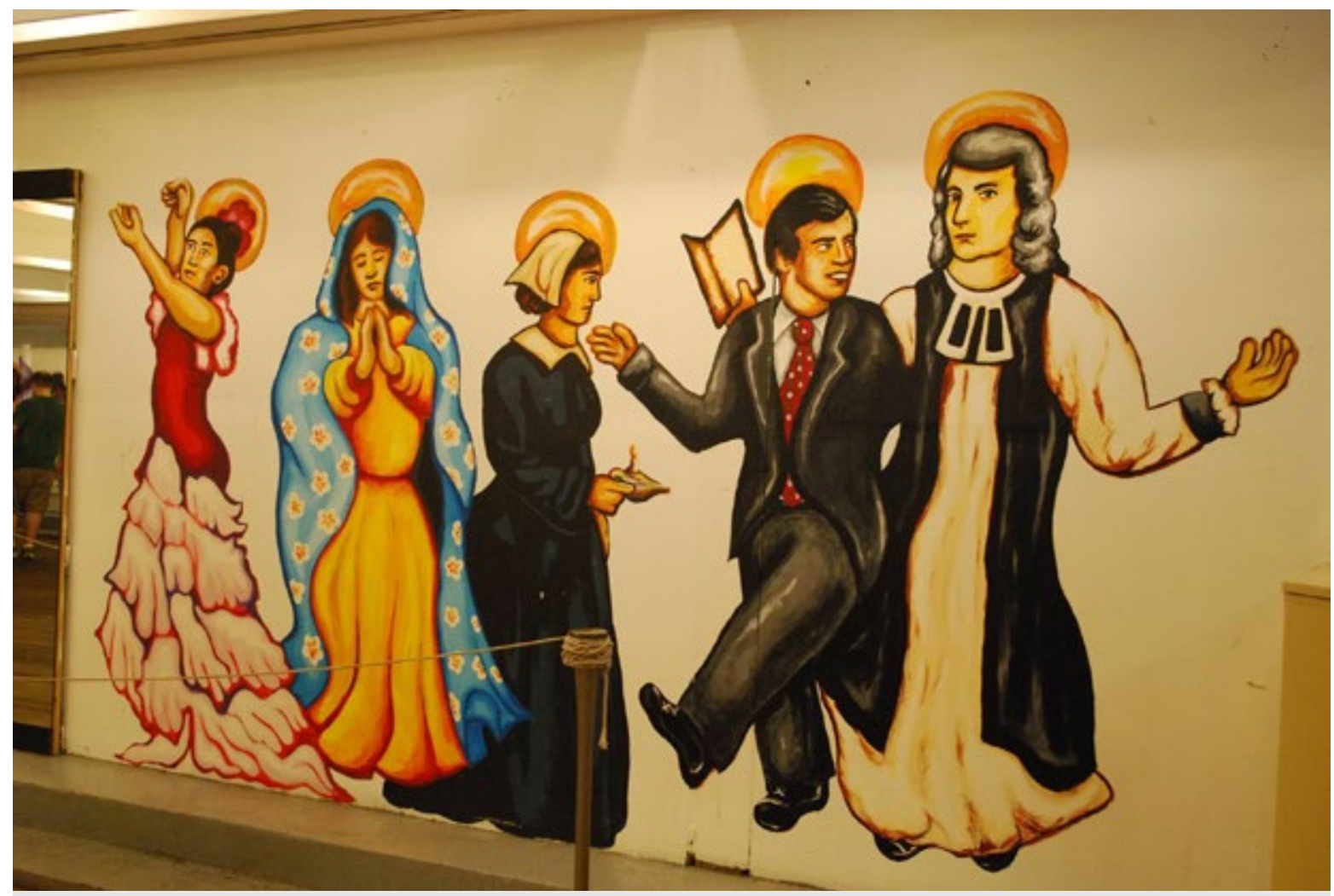

Detail of Dickerson's Dance with the Saints mural 
Julie Dickerson: I think this [St. Paul and St. James] is the only place where that could have been an issue, like if someone got really upset over a certain saint being on the wall or something, but my default answer for that is “I didn't make the list." I think you're always prepared to hear someone say something. It's really hard to make anything in life that everyone likes. In this case I don't need to worry so much because it's almost not my problem.

Ashley Makar: How do you navigate the potential for division and challenge that can arise over artistic work that engages with religious practices and/or content?

Julie Dickerson: That's a tough one. This is the only one I've done with religious content, but in terms of preparing for someone saying, "Why is that person on there?" or whatever, I would probably just say, "Well, no one's perfect, but the reason he was picked, she was picked, was for this reason." I also feel that a lot of people who use this space, especially the NA [Narcotics Anonymous] people who aren't necessarily associated with any religious organizations but do believe in a higher power, you would have to work pretty hard to offend them. They're here to be open. After meeting the people I didn't even think about there being any controversy. That was something that Alex and I talked about. You kind of need the whole range of people [in the mural], even less religious people on here, because then when you look in the mirror and see yourself with all of them you say, "Oh, okay, this is not something that's so removed from me." There are people who are like, "I'm a musician, I see musicians in there," and they feel represented. In this case having it be less traditional makes it more inclusive, which, in my opinion, should be the traditional Christian value of acceptance and opening the doors to as many people as possible. Even though it's "less traditional" it's more traditional in its values.

[The mirror] was something they came to me having thought about already. I thought the idea was amazing. This is the first time where there is another element other than paint that purposely plays into how the mural is viewed. So that's really exciting.

Ashley Makar: Do you have an interest in producing resources for religious/spiritual communities and/or individuals?

Julie Dickerson: I am raising money for Haiti by doing an assignment. There was a local church where I said, "Do you think the congregation would be interested in supporting me?" But churches give so much for free and I hate to be the person to ask for one more thing. So what my art does is give me a chance to say look, if we raise whatever amount the pastor thinks is reasonable, not too cheap but clearly not too much, if we raise whatever amount he says, I will paint a mural in the church. I don't want to just take from certain people and give to others. I would like to have it be: you're giving, I'm giving, and eventually these people will be giving back to the community as well. Once Haiti builds itself up they are going to give back. I want it to be more about giving than anything else. 


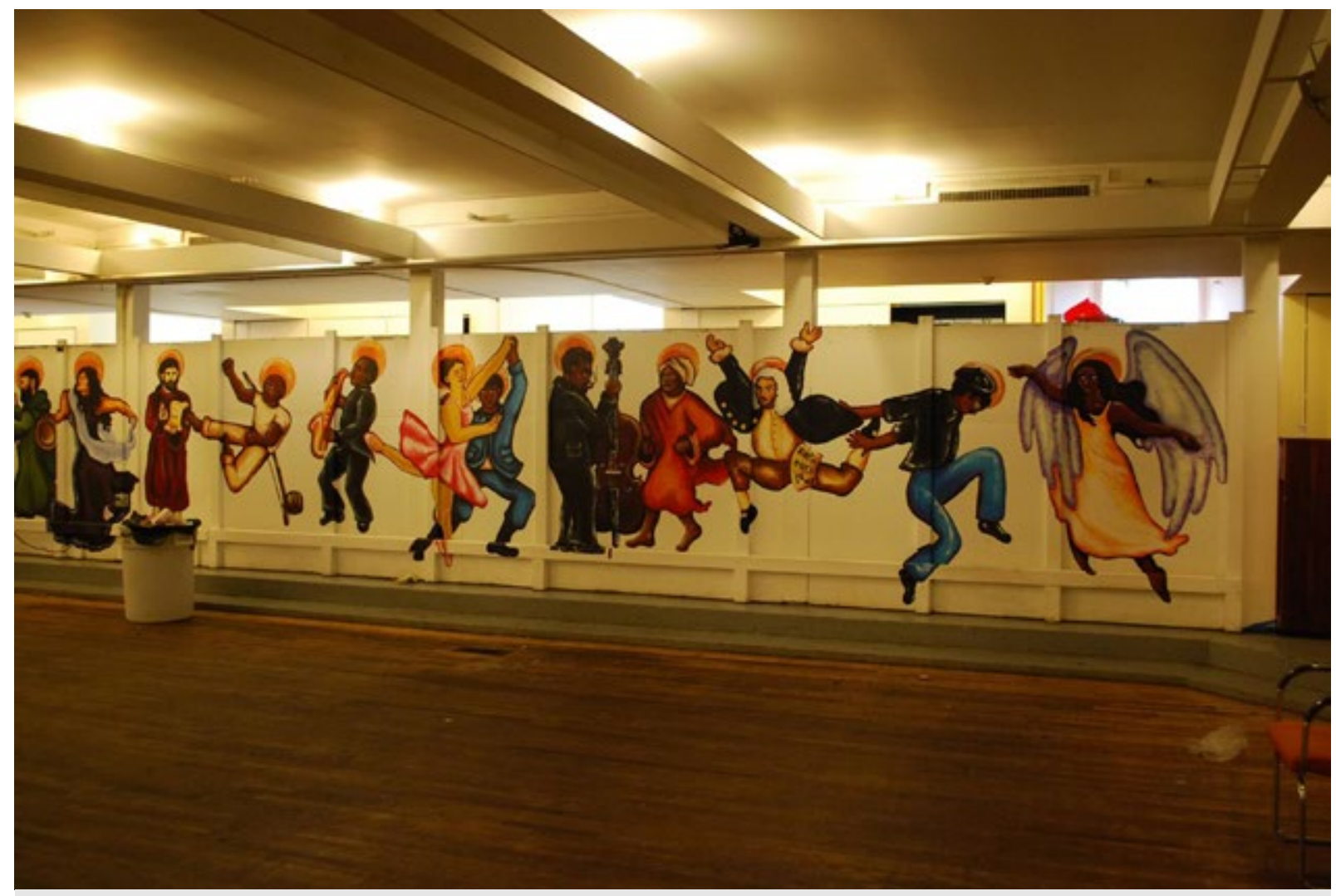

Detail of Dickerson's Dance with the Saints mural

Ashley Makar: Do you have a particular interest in working with institutions and/or groups that perform some sort of religious identity?

Julie Dickerson: I didn't set out doing that, it definitely just happened. I respond to the people who get back to me. I email a bunch of places and the people who get back to me, that's who I paint for. A lot of those do happen to be religious groups. I don't know if you can draw a conclusion from that. A lot of people are volunteers so they are doing it because they really want to, not because they have to. I think that gives them more time to read over my email and see "Oh, this person isn't just a weirdo who wants to come and paint for free." They have the time to talk to me about what's going on without feeling extra pressure. Some groups that aren't volunteer, I can't really say this for sure because I don't have enough experience, but I can imagine there's so many issues going on that, it's like their last priority. People who are staffed with volunteers, they are already volunteers so they don't mind giving - they're also not held to as many strict protocols. But that's kind of a guess, I don't actually know about it.

Ashley Makar: Well I can't believe that whole area [of the mural] over there.

Julie Dickerson: There's this one guy from NA who wants to help every single meeting so he'll fill in blocks of color and stuff. Today he said, "I want to learn more detail." I said, "I'm under a time limit, I can't spend a lot of time teaching you, but look, we'll do a little bit, we'll do a little bit." It's really tough. I like talking to the people, they want to 
talk about deep stuff, which I also enjoy doing, but if I'm trying to paint, and teach, and listen to him, and he's hungry, it becomes overwhelming really quick.

Ashley Makar: You feel like you can’t be a painting teacher and a therapist.

Julie Dickerson: Yes, I like listening, but it's hard for me. I can paint and talk just fine, but painting and talking about someone's personal life and giving an appropriate response, that's tough. I can answer questions about me fine, but if I'm trying to think about them and where they're coming from, that's difficult.

(C) Ashley Makar

\section{Citation Guide}

1. "Julie Dickerson: Creative Currents," by Ashley Makar, Interview, in Conversations: An Online Journal of the Center for the Study of Material and Visual Cultures of Religion (2014), doi:10.22332/con.int.2014.4

"Julie Dickerson: Creative Currents." By Ashley Makar. Interview. In Conversations: An Online Journal of the Center for the Study of Material and Visual Cultures of Religion (2014). doi:10.22332/con.int.2014.4

\section{Notes}

1. Reverend Alex Dyer is priest in charge at St. Paul and St. James.

2. Dickerson is referring to the passage in Luke 10:38-42 in which Jesus and his disciples stay in the home of two sisters named Mary and Martha. While Martha works hard preparing for their guests, Mary sits with Jesus and listens to his teachings. Martha, angry that her sister is not helping her, protests to Jesus, who tells her that Mary has made the better choice.

\section{Yale}

Copyright 2016 Yale University All rights reserved. 